\title{
Prioridades de pesquisa em enfermagem neonatal e pediátrica
}

\section{Thaíla Corrêa Castral ${ }^{1}$, Mariana Firmino Daré ${ }^{2}$, Carmen Gracinda Silvan Scochi ${ }^{3}$}

\author{
${ }^{1}$ Enfermeira, Doutora em Ciências. Professora Adjunto I da Faculdade de Enfermagem da Universidade Federal de Goiás. Goiânia, Goiás, Brasil. E-mail: \\ thaccastral@gmail.com. \\ 2 Enfermeira. Doutoranda do Programa de Pós-Graduação Enfermagem em Saúde Pública Escola de Enfermagem de Ribeirão Preto da Universidade de São \\ Paulo (EERP/USP). Bolsista Regular de Doutorado Direto FAPESP. Ribeirão Preto, São Paulo, Brasil. E-mail: mari dare@hotmail.com. \\ ${ }^{3}$ Enfermeira, Livre-Docente. Professora Titular do Departamento de Enfermagem Materno-Infantil e Saúde Pública da EERP/USP. Bolsista Produtividade em \\ Pesquisa 1B do CNPq. Coordenadora da Área de Enfermagem na CAPES. Ribeirão Preto, São Paulo, Brasil. E-mail: cscochi@eerp.usp.br.
}

No Brasil, a Enfermagem representa cerca de $60 \%$ (R $\$ 1,3$ milhão) dos recursos humanos do Sistema Único de Saúde (SUS), com grande contribuição na atenção à saúde da população. Destaca-se, na atualidade, a premente necessidade de acelerar o processo de utilização dos resultados de pesquisas científicas na prática e, neste contexto, o conhecimento científico da Enfermagem tem potencial para melhorar os resultados da área da saúde e avançar em tecnologias inovadoras de cuidado.

A produção de conhecimento da Enfermagem brasileira está em franco desenvolvimento, articulada ao crescimento da pós-graduação na área, com repercussões na sua visibilidade nacional e internacional. Assim, em 2012, alcançamos o $6^{\circ}$ lugar no ranking mundial de publicações na base SCImago Journal \& Country Rank (SCImago). A área também cresceu em relação à sua contribuição na produção científica do Brasil, visto que representava $0,2 \%$ do conhecimento divulgado nessa base de dados em 2005, passando a 1,9\%, em 2012. Portanto, computa-se crescimento relativo de $713 \%$, muito superior àquele ocorrido em áreas da saúde mais consolidadas, como a Medicina (6,2\%) e a Odontologia $(53 \%)$.

Considerando que muito dessa produção é resultado da pós-graduação na área, e diante da temática proposta para este editorial, motivamo-nos a investigar a contribuição da produção de conhecimento na área de Enfermagem Pediátrica e Neonatal a partir das teses e dissertações. Assim, com o objetivo de caracterizar as pesquisas realizadas sobre a atenção ao recém-nascido, criança, adolescente e família, realizamos um levantamento dos resumos de teses e dissertações defendidas no triênio 2010-2012, registrados no Sistema de Coleta da Coordenação de Aperfeiçoamento de Pessoal de Nível Superior (Capes), segundo as três grandes áreas e linhas de pesquisa da área de Enfermagem propostas pela CAPES, Conselho Nacional de Desenvolvimento Científico e Tecnológico (CNPq) e Associação Brasileira de Enfermagem (ABEn) em 2001 durante o $11^{\circ}$ Seminário Nacional de Pesquisa em Enfermagem ${ }^{(1)}$, temáticas e abordagens. O critério para seleção dos resumos foi a investigação sobre a temática e/ou inclusão do recém-nascido, da criança, do adolescente e de sua família como sujeito(s) do estudo.

Dos 2.860 resumos analisados (502 teses e 2.178 dissertações), 343 (12,7\%) atenderam aos critérios de inclusão, sendo que o descritor Enfermagem Pediátrica foi citado apenas em oito resumos e quatro vezes como palavras-chave, enquanto o descritor Enfermagem Neonatal foi citado em dois resumos e utilizado duas vezes como palavras-chave.

Em relação às grandes áreas de pesquisa, predominou o campo assistencial com 209 (61\%) teses e dissertações, seguido do organizacional com 103 (30\%) e do professional com 31 (9\%). Na área assistencial, predominou a produção na linha de pesquisa Processo de Cuidar em Saúde e Enfermagem (174 teses e dissertações); na área organizacional, destacaram-se duas linhas Políticas e Práticas em Saúde e Enfermagem (39) e de Educação e Enfermagem (36), e na área profissional predominou a linha de pesquisa Tecnologia em Saúde e Enfermagem (19).

Os temas mais frequentemente abordados foram: família, criança com câncer, aleitamento materno, violência, dor, tecnologia de cuidado (educação em saúde, sistematização da assistência de Enfermagem - SAE) e processo saúdedoença (percepção e educação em saúde).

No processo de cuidar, predominaram as seguintes temáticas, de acordo com as diferentes faixas etárias da criança: recém-nascido - aleitamento materno e dor; criança - a hospitalização e condições crônicas (câncer, HIV e diabetes melitus); escolar - hospitalização e educação em saúde; adolescente - gravidez e sexualidade. Quanto ao tema família, predominaram estudos sobre o cuidado do filho na hospitalização e na doença, sua percepção e vivências nesse processo (como, por exemplo, itinerário terapêutico e saúde mental), bem como sobre a perspectiva do profissional acerca do cuidado à família. 
Percebe-se que as teses e dissertações em Enfermagem Pediátrica e Neonatal têm suas temáticas em consonância com as necessidades de saúde desse segmento populacional ${ }^{(2)}$ e com as políticas públicas de saúde da criança e adolescente ${ }^{(3-4)}$.

A grande maioria dos estudos revisados eram descritivos, o que também predominou no conjunto das teses e dissertações defendidas no período de 2010-2012 na Enfermagem ${ }^{(5)}$. Apenas 23 (6,7\%) dos resumos eram de intervenção, a maioria de educação em saúde da criança/adolescente ou família; 14 (4\%) ensaios clínicos ou quase experimentos; 14 (4\%) estudos metodológicos que criaram e validaram instrumentos de medida, e 3,5\% (12) abordam o desenvolvimento de produtos e processos para o cuidado e/ou ensino (software, objetos virtuais de aprendizagem, cartilhas, protocolo, escala, SAE).

A abordagem qualitativa (195) predominou nas teses e dissertações, sendo que $49 \%$ explicitaram algum referencial teórico (Representações Sociais - 12, Dialética - 11 e Interacionismo Simbólico - 6) e 35\% utilizaram o método da análise de conteúdo.

Cabe como limitação deste estudo o recorte temporal e a fonte de dados utilizados, destacando-se a falta de informação acerca do desenho e resultados obtidos nos resumos das teses e dissertações analisados.

Todavia, o cenário apontado da produção da Enfermagem Pediátrica e Neonatal brasileira nos impulsiona para inquietações acerca do impacto de nossas pesquisas na prática profissional e se esta realmente está fundamentada em evidências, emergindo alguns questionamentos:

$\checkmark$ Será que as pesquisas em desenvolvimento estão respondendo às necessidades advindas da prática de Enfermagem Pediátrica e Neonatal?

$\checkmark \quad$ Será que o conhecimento que estamos produzindo tem respondido às necessidades de saúde e qualidade de vida do neonato, da criança, do adolescente e sua família? Estão em consonância com as prioridades de pesquisa em saúde?

$\checkmark \quad$ Será que os resultados das pesquisas têm sido incorporados na prática assistencial e de ensino?

$\checkmark$ Como pesquisadores e instituições têm se posicionado quanto à transferência de conhecimento na prática de Enfermagem Neonatal e Pediátrica?

Apontamos a seguir alguns desafios a serem enfrentados visando a um maior impacto da pesquisa em Enfermagem Neonatal e Pediátrica na prática profissional:

$\checkmark \quad$ Incrementar a formação de enfermeiros com perfil proativo, criativo e de liderança no uso de evidências e do método científico na tomada de decisão.

$\checkmark$ Mobilizar a participação dos enfermeiros em comitês de pesquisa-prática e em redes/grupos de atenção e pesquisa com foco no cuidado enquanto promotor da vida com qualidade, do conforto, do empoderamento dos sujeitos individuais e coletivos no contexto da atenção à saúde da criança e do adolescente.

$\checkmark$ Gerar e disseminar conhecimentos inovadores, incrementando o desenvolvimento de tecnologia e de projetos mais arrojados, ensaios clínicos, abordagens qualitativas densas e outras que agreguem ao processo de investigação a mudança na prática, com transferência de conhecimento, e que mostrem o custo efetividade na implementação de práticas de cuidado e gestão em Enfermagem Pediátrica e Neonatal.

$\checkmark$ Incrementar a pós-graduação latu sensu (especialização, aperfeiçoamento, residência) articulada às necessidades de saúde da criança e do adolescente, das políticas de saúde e do mercado de trabalho. Na pósgraduação stricto sensu, incrementar a modalidade de mestrado profissional, reduzindo a lacuna entre conhecimento e prática clínica e, para o mestrado e doutorado acadêmicos, fortalecer a formação em pesquisa, as linhas e os grupos de pesquisa que possuem projetos de pesquisa e extensão sobre o cuidado de Enfermagem ao recém-nascido, criança, adolescente e sua família.

$\checkmark$ Implementar a atuação das sociedades científicas brasileiras no estabelecimento de políticas, diretrizes e protocolos de cuidado, criando comitês de consenso.

Cabe ainda, destacar as recomendações da ABEn, por ocasião do $65^{\circ}$ Congresso Brasileiro de Enfermagem, realizado em outubro de 2013 no Rio de Janeiro, em especial aquela relativa ao desenvolvimento de estratégias para o cumprimento das Diretrizes Curriculares Nacionais do Curso de Graduação em Enfermagem, principalmente no que diz respeito ao desenvolvimento, participação e aplicação de pesquisas e/ou outras formas de produção de conhecimento que objetivem a qualificação da prática profissional. 
Neste sentido, este número da Revista Eletrônica de Enfermagem contém cinco artigos originais relevantes para a área da Enfermagem Pediátrica e Neonatal. Os estudos têm como temáticas o diagnóstico de enfermagem em crianças com infecções respiratórias, imunização infantil, vulnerabilidade na infância, fatores relacionados ao trauma vascular periférico em crianças e o uso de estudo de caso para o ensino do raciocínio diagnóstico. Os resultados são relevantes para a implementação de intervenções mais eficazes, favorecendo a qualidade da assistência prestada aos recémnascidos, crianças e família.

\section{REFERÊNCIAS}

1. Carvalho V. Linhas de pesquisa e prioridades de enfermagem: proposta com distinção gnoseológica para o agrupamento da produção científica de pós-graduação em enfermagem. Esc. Anna Nery. 2002;6(1):145-54.

2. Lansky S, França E. Mortalidade infantil neonatal no Brasil: situação, tendências e perspectivas. In: Rede Interagencial de Informações para Saúde. Demografia e Saúde: contribuição para análise de situação e tendências [Internet]. Brasília: OPAS; 2009 [acesso em: 20 mar 2014]. p. 83-112. Disponível em: http://www.ripsa.org.br/local/docsonline/6/7/276-

livro_demografia_e saude_WEB.pdf.

3. Ministério da Saúde. Plano Nacional de Saúde-PNS:2012-2015. Brasília (Brasil): Ministério da Saúde; 2011 [acesso em: 20 mar 2014]. 114 p. Disponível em: http://conselho.saude.gov.br/biblioteca/Relatorios/plano_nacional_saude_2012_2015.pdf.

4. Ministério da Saúde. Agenda nacional de prioridades de pesquisa em saúde [Internet]. 2a ed. Brasília (Brasil): Ministério da Saúde; 2008 [acesso em: 20 mar 2014]. 68 p. Disponível em:

http://bvsms.saude.gov.br/bvs/publicacoes/AGENDA_PORTUGUES MONTADO.pdf.

5. Munari DB, Chaves LDP, Peduzzi M, Laus AM, Fugulin FMT, Ribeiro LCM, Scochi CGS. The setting of research production by nursing and management graduate programs in Brazil. Rev Esc Enferm USP [Internet]. 2011 [acesso em: 20 mar 2014];45(esp):1543-50. Disponível em: http://dx.doi.org/10.1590/S0080-62342011000700002. 